occur till embryonic development has proceeded far enough to start the formation of the organs implicated; and the heart, for example, is perfectly formed, though in miniature, by the end of the seventh week after conception. ${ }^{2}$ By analogy it is argued that similarly the Mongolian characteristics (which are in effect congenital malformations) take their origin in the embryonic ${ }^{3}$ period of the fir'st six weeks of intrauterine life. This mar be countered by the argument that an ovum already the subject of an inherent defect (of a nature which is wonderfully true to type) is more likely to go wrong in other directions than one which is not.

David M. Greig, in a recent long and erudite article, ${ }^{4}$ favours a theory that Mongolism is a defect of foetal grovth, though he concludes that this must have started in the embryonic period mentioned already. He bases on his minute and fully recorded observations on three Mongolian skulls the deduction that Mongolism "seems rather to be a defect in growth (foetal) than a defect in development (embryonic)." $\mathrm{He}$ states that "the main defect in the skull is want of growth of the facial bones, chiefly the maxillae and of the alveolar processes anteriorly," with various consequences to the adjacent bones, into which I need not enter. As an interesting aside, however, it may be mentioned that although obliquity of the palpebral fissures and nearness of the eyes are characteristic of the Mongolian facies, there was no obliquity of the superciliary margins in these skulls, nor any undue approximation of the bony orbits. With regard to the reported arrest of development of the skull base he goes on to say: "Deficiency of the anterior wall of the acoustic meatus, imperfect closure of the foramen ovale and foramen spinosum, flatness of the occipital condyles, and in the youngest skull an indication of the component parts of the occipital bone, are evidences of delayed development, but are not features which have interfered with the growth or size of the skull-base. If any arrest of development has occurred it is in the brain, not in the bones..."; and later, "Before the age of 16 the growth of the Mongol's brain has ceased." He states as his final opinion that " even from the skull alone there seems evidence that development normally begun has mapped out all structures and features in the embryo, but has failed to lead them to perfection during foetal growth." Pointing out that the first appearance of ossification in the skull appears in the maxillae on the thirty-ninth day, followed by the premaxilla three days later, and the nasal bones on the fiftyseventh day, he says: "Obviously it is during this period that the departure from normal growth shows itself, and this failure in the bones is accompanied or followed by defective growth elsewhere, notably in the nervous system."

For myself, though open to conviction, I believe the maternal influence, which appears to be almost undeniable, and whatever it may be, is exercised upon the ovum during its maturation, and therefore before fertilization has foliowed and segmentation started.

The chief argument in favour of this theory is the occasional occurrence of twins one of which is Mongol and the other not. This proves beyond a doubt that no maternal influence is present after embryonic development has begun; or that if there be any such influence it is selective in a manner highly improbable, though I recognize this argument is a two-edged sword. It has no bearing on the question of responsibility as between the parents, for obviously if one ovum can be inherently Mongol and the other not so, the same should hold good of the male elements. Known cases of twins both of which were Mongols are so rare-only some three in number-and their original records so inaccessible that although they were of the same sex complete proof that they resulted from uniovular pregnancies is wanting, but the assumption that it was so is warranted. There are also three cases on record where the twins were of the same sex, one being Mongol; but there is equally no proof that these were uniovular pregnancies. But on no occasion has it yet been recorded that twins of different sex were both Mongols, which is in accordance with the mathematical probabilities under this theory. Though the theory does not prohibit the possibility of binovular twins being Mongols it must be remembered that, apart from the six twin cases above mentioned, and admitting the fact that the Mongol is often the last pregnancy, more than one Mongol in a family is almost, if not quite, unknown. But we are still as far as ever from solving the problem of the malign influence dooming the orum to Mongolism, and the corollary of prevention.

In January, 1923, Halbertsma of Haarlem ${ }^{5}$ collected fifteen cases of twin pregnancies of which one twin was Mongol and the other normal. Occasional additions to this list have since been made, and to these $I \mathrm{am}$ able to add another instance.

On December 23rd, 1926, C. F., aged 4 months, was brought to the Royal "Liverpool Children's Hospital because " he was not coming on." He was one of twins, the other being a girl, who, at my request, was brought on a subsequent occasion parison, and proved to be a normal and healthy child, though small for her age. The boy had the typical Mongolian crania attributes and facial appearance, with the other characteristics
of the Mongolian imbecile, including the loud bruit and the of the Mongolian imbecile, including the loud bruit and the
cyanosis of a congenital heart lesion. This child further complied with the frequent Mongolian history by dying of measles, contracted when he was 14 months old. The sister recovered.

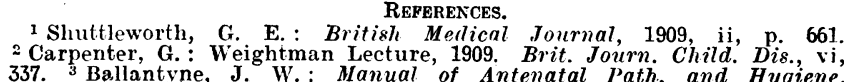
337. 3 Ballantyne, J. W. W Manual of Antenatal Path. and Hygiene, The Embryo, 1904, iii. 1 Eulin. M M
s Amer. Journ. Dis. C'hild., xxv, 352 .

\section{A CASE OF PRIMARY ACTINOMYCOSIS OF THE LUNG.}

HERBERT SHARPE, M.R.C.S., L.R.C.P., MEDICAL SUPERINTENDENT, WARE PARK SANATORIUM, HERTS.

Owse to the fact that patients admitted to tuberculosis sanatoriums have mostly been diagnosed before admission one is apt to be biased in favour of tuberculous infection and to take for granted that the diagnosis is correct, instead of approaching the case with an open mind. During the course of the illness of a certain patient one or two complications ensued which raised some doubt as to the diagnosis of pulmonary tuberculosis being correct; hence I have thought it worth while to publish an account of the case.

Prrious History-Up to the age of 18 the patient had lived in South Africa, where, after leaving school, he was an apprentic in a lithography works. He came to England for a few months holiday, and then went to Australia with a friend to search for gold. After a few months of unsuccessful prospecting they both worked on a ranch, sheep farming, for about eighteen months or two years. The patient then joined the army soon after the outbreak of war. He was sent to England and thence to France, where he was "gassed" in March,. 1918; his war service amounted in all to three and three-quarter years when he was amounted in all to three and three-quarter years when he was remained at this work for four years. He returned to England, remained at this work for four years. He returned to England,
and after three months' holiday worked as a bricklayer for five months, later returning to his original work as a lithographer. His health gradually deteriorated, but he remained at work until June, 1927, when he complained of acute pain in the left side, anorexia, and loss of weight. $\mathrm{He}$ was first seen by a tuberculosis officer in October of that year, who, after having carefully watched the temperature $\left(99.2^{\circ}-102^{\circ}\right)$ for a few days diagnosed the case as anaemia and pleurisy with effusion, and diagnosed the case as anaemia and pleurisy with effusion, and
recommended sanatorium treatment. The sputum had been examined a month previously, with a negative result. There examined a month previously, with a negative result. There
was no significant family history and no previous illness of importance.

Condition on Admission.-The patient was admitted to the Hertfordshire County Sanatorium on October 24th, 1927. He gave his age as 35, was very anaemic, and looked exceedingly ill. night's rest for a fortnight. His temperature was $100^{\circ} \mathrm{F}$., pulse 118 , and respirations 24 . He complained of pain extending from the right shoulder down the outer side of the arm as far as the right shoulder down the outer side of the arm as far as
the elbow, but since no definite lesion could be found to cause the elbow, but since no definite lesion could be found to cause the pain, it was attributed to neuritis. On examination of the
chest the left side was folnd to be dull on percussion, the chest the left side was found to be dull on percussion, the
dullness being most marked at the left base posteriorly. There was also slight impairment of the note at the right apex. There were moist crepitations throughout the left side, and in addition diminished breath sounds at the base behind with amphoric breathing-signs compatible with pleurisy with a small effusion. His liver was palpable and slightly tender; the abdomen otherwise revealed no abnormalities. The urine contained no albumin wise revealed no abnormalities. The urine contained no albu.
or sugar; the specific gravity was 1020 and the reaction acid.

Subscquent History. - The pain down his right. arm was treated Subsequent History. - The pain down his right. arm was treated
with methyl salicylate and a neuralgia mixture was given. Nepenthe $20 \mathrm{~m}$ was ordered, and the next day he appeared to 
be somewhat easier. Between November 1st and December 24th, ten abscesses developed in various parts of the body, most of which were aspirated or incised under novocain. On two occasions pis was sent for bacteriological examination and inoculation of a guinea-pig requested. "The first report was as follows: "Thick a guinea-pig requested. The first report was as follows: "Thick grumous from red blood corpuscles. Tubercle bacilli could not be apart from red blood corpuscles. Tubercle bacilli could not be " Microscopically it is essentially structureless, only a few celloutlines being seen. Tubercle bacilli could not be found either by direct films or by concentration methods. No other microorganisms wero found on microscopic examination and cultures remained sterile. Animal inoculation of the material for tubercle bacilli is being proceeded with."

During this time the patient's temperature and pulse remained about the same, his general condition seemed to be improving, but the signs in his chest were unaltered. The Wassermaun reaction was negative, as also were blood tests for typhoid and parat"yhoid infections. On December 12th his temperature began to subsiae, it being $98.4^{\circ} \mathrm{F}$. in the morning and $100^{\circ} \mathrm{F}$. in the evening; between December 18th and 22nd it remained between $97.2^{\circ} \mathrm{F}$. and $98.8^{\circ} \mathrm{F}$. On December $23 \mathrm{rd}$ it became subnormal, and remained so until his death six days later. The pulse rate, on the other hand, never dropped-below 100, ranging between 100 and 120 , with respirations constant at 24 .

Special features as regards the case from a differential diagnostic point of view were: (1) all the abscesses developed very quickly; (2) they caused great pain; (3) after the first had been incised the pus, which was quite innocuous, became so fetid that the patient had to be removed from the ward into a separate shelter; (4) the relief experienced after incision and aspiration was very considerable.

A. post-mortem examination was performed on December 30th by Dr. G. H. Pringle and myself, and the following observations were made.

There were adhesions on the left side between the left lung and chest wall, becoming denser towards the base. A large abscess was found in the base of the left lung, which showed collapse. Both lobes on the left side and the two upper lobes on the right contained numerous small nodules, which proved to be abscesses. The heart was small, and there was an ounce of greenish fluid in the pericardial sac. There was slight atheroma of the aorta, a little thickening around the pulmonary orifice, and a small abscess in the wall of the left ventricle. Other abscesses were found in the following organs: two in the liver which was congested and fibrous; one in the left kidney, round which were adhesions; a perinephric abscess, which communicated which were adhesions; a perinephric abscess, which communicated
with the one in the lower part of the left lung through an opening in the diaphragm (the right kidney was normal); and one in the spleen, which was slightly enlarged and friable. There were a - few small flattened greyish nodules in the mesentery, but no peritoneal adhesions.

Portions of the abscess tissues from the liver, lungs, and heart were examined histologically, and the organism responsible for the condition was found to be the actinomyces. The tissue was remarkable in showing a large number of granules, which is rare in human actinomycosis. The guinea-pigs inoculated showed no signs of tuberculous infection, and the pus was presumably, therefore, free from tubercle bacilli.

My thanks are due to Dr. H. Hyslop Thomson, county medical officer of health, for permission to publish this account, and for his assistance, also to Dr. G. H. Pringle for his help in the investigation.

\section{AN ADJUSTABLE BOARD-BED.}

LEONARD HEARN, M.B., B.S.DURH.,

LATE RESIDENT MEDICAL OFFICER, HULL TUBERCULOSIS SANATORIUM, COTTINGHAM, E. YORKS.

Túbercurous disease of the hip is unfortunately only too often met with for the first time when the condition is well established and the joint is more or less fixed, with the linib in a bad position of adduction, inward rotation and flexion, and usually a certain amount of shortening. The bed splint to be described has been used with excellent results; it is designed to correct tho defornity very gradually and obtain the desired position, with a quiescent condition, before the limb is put up in a plaster splint.

All tuberculous lesions improve as the general condition of the patient grows better, and these cases should be placed on the open verandah day and night in all seasons. 'This bed splint enables the patients to be treated under open-air conditions; they are really only confined to bec like pyrexial pulmonary cases, and enjoy a maximum amount of comfort, thus benefiting both morally and physically. Often in cases of tuberculous disease of the hip-joint the limb is fixed in plaster, or in a Thomas's hip splint, in a more or less good position, but this unfortunately may entail a compensatory lordosis of the spine, with subsequent permanent deformity.

This apparatus is essentially a " board-bed," hinged in the middle so that the lower half supporting the legs may be raised or lowered at will by means of a support on a ratchet similar to the method of fixing an ordinary deck chair. Six boards form a box frame for retaining the patient in position, and these swivel from the centre line

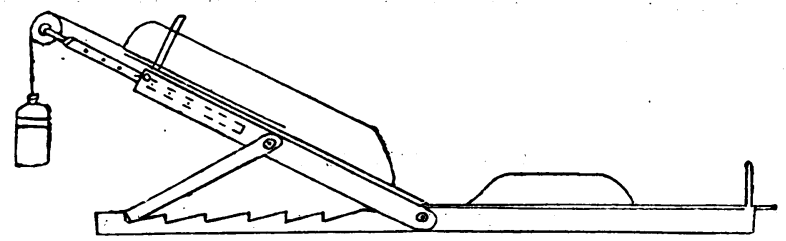

of the bed; they are kept. in position by means of pegs in rows of holes at the foot and head. The lower end of the frame can be extended to fit any length of patient, and, the boards being $3 \frac{1}{2}$ to 4 inches high, cradles are unnecessary. Pulleys adjusted by means of thumbscrews carry the extension weights, and move to any position on the lower edge of the franie.

At the commencement of treatment the spine is placed in its natural position, with the limbs raised and with a suitable extension weight applied, the affected joint is gradually abducted, and the leg is lowered as required, the position of the spine not being allowed to vary, so that lordosis is never preseitit.

The case shown is a typical tuberculous arthritis of the left hip; this joint was held in a bad position of flexion and adduction, with two inches of shortening. There were present also all the symptoms of active disease, such as pain, heat, and pyrexia.

The first photograph demonstrates the amount of compensatory lordosis which was present when the affected

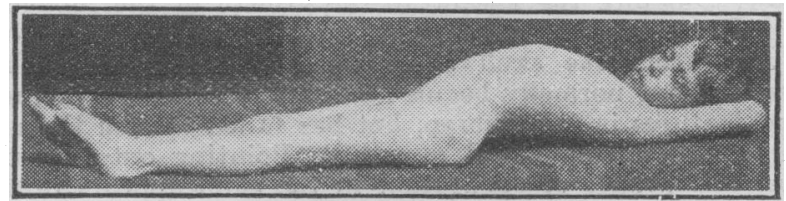

ley was kept flat to correspond with the sound leg; this is the position in which so many limbs, after abduction and external rotation, are finally fixed in a plaster-of-Paris or

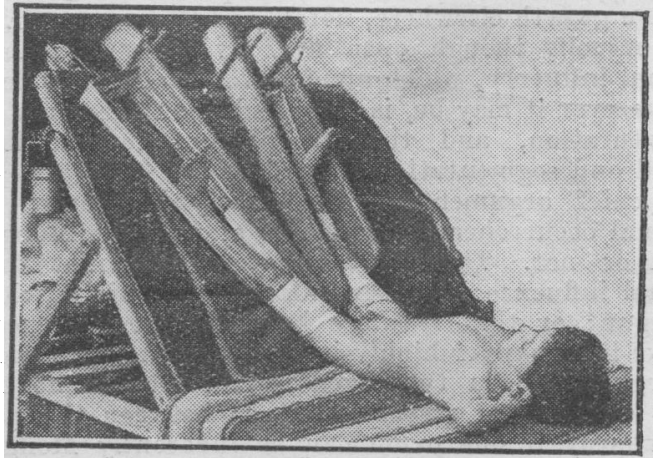

Thomas's splint. The second photograph shows the patient in position at the commencement of treatment, with the spino in normal position. In the third the corrected limb

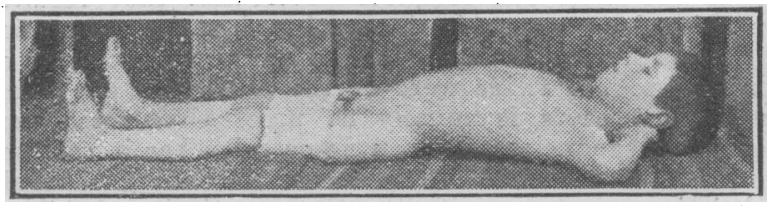

is seen after use of the board-bed and ready to be put up in plaster-of-Paris, after having been submitted to very gradual lowering and extension, dependent on the position of the spine. 